\title{
Embryo development of prepubertal goat oocytes fertilised by intracytoplasmic sperm injection (ICSI) according to oocyte diameter
}

\author{
Ana-Raquel Jiménez-Macedo a , Begoña Anguita ${ }^{a}$, Dolors Izquierdo ${ }^{a}$, \\ Teresa Mogas ${ }^{\mathrm{b}}$, Maria-Teresa Paramio ${ }^{\mathrm{a}, *}$ \\ ${ }^{a}$ Departament de Ciència Animal i dels Aliments, Facultat de Veterinària, \\ Universitat Autònoma de Barcelona, Bellaterra 08183, Barcelona, Spain \\ ${ }^{\mathrm{b}}$ Departament de Medicina i Cirugía Animal, Facultat de Veterinària, \\ Universitat Autònoma de Barcelona, Bellaterra, Barcelona, Spain
}

Received 18 January 2006; received in revised form 2 March 2006; accepted 4 March 2006

\begin{abstract}
The aim of this study was to evaluate embryo development of prepubertal goat oocytes fertilised by ICSI according to their diameter. Three experiments were carried out to achieve this objective. In all experiments, oocytes were matured in TCM199 supplemented with hormones, cysteamine and serum for $27 \mathrm{~h}$ at $38.5^{\circ} \mathrm{C}$. In Experiment 1, we studied the nuclear stage of goat zygotes produced by conventional ICSI and IVF using $20 \mathrm{nM}$ ionomycin plus $10 \mu \mathrm{M}$ heparin as sperm treatment. A group of Shaminjected oocytes was used as control. Results showed differences in the percentage of 2 PN (zygotes with male and female pronuclei) between ICSI, IVF and Sham (40.9, 26.6 and 3.0\%, respectively; $P<0.05$ ). In Experiment 2, we evaluated the embryo development of prepubertal goat oocytes produced by ICSI and IVF after $192 \mathrm{~h}$ of culture in SOF medium. The percentage of morulae plus blastocysts obtained was higher in the ICSI than in the IVF group (13.4 and 5.1\%, respectively; $P<0.05$ ). In Experiment 3, IVM-oocytes were classified in four groups depending on their diameter (Group A: $<110 \mu \mathrm{m}$; Group B: 110$125 \mu \mathrm{m}$; Group C: 125-135 $\mu \mathrm{m}$; Group D: $>135 \mu \mathrm{m}$ ), fertilised by ICSI and cultured for $192 \mathrm{~h}$. Results showed a positive correlation between oocyte diameter and embryo development (morulae + blastocysts: Group A: 0\%; Group B: 6.2\%; Group C: 46.4\% and Group D: $33.3 \%$ ).

In conclusion, sperm treatment with ionomycin plus heparin using the conventional ICSI protocol improved fertilisation rates in comparison to IVF. Oocytes smaller than $125 \mu \mathrm{m}$ were unable to develop up to blastocyst stage.
\end{abstract}

(C) 2006 Published by Elsevier Inc.

Keywords: ICSI; Oocyte diameter; Goat; Prepubertal

\section{Introduction}

The success of in vitro fertilisation (IVF) is dependent on both sperm maturation and capacitation for penetration of the oocyte and on oocyte quality to support embryo development. Unfortunately, IVF does

\footnotetext{
* Corresponding author. Tel.: +34 935811456; fax: +34 935811494.

E-mail address: teresa.paramio@uab.es (M.-T. Paramio).
}

not always provide good results because of male infertility or high fertilisation abnormalities (such as polyspermy) found using this procedure. In order to bypass this step and minimize variability due to sperm capacitation and penetration, intracytoplasmic sperm injection (ICSI) could be used as a technique for sperm and oocyte quality evaluation studies.

The ICSI is a fertilisation technique that involves mechanical injection of a single sperm into the oocyte. 
This technique was first reported in sea urchins [1] but only when Uehara and Yanahimashi [2] obtained good results in hamsters, was ICSI tested with success in other species (mice [3]; sheep [4]; horse [5]; pig [6]; cattle [7]; goats [8,9]). The success of ICSI depends on the protocol used for each species. In some species, fertilisation and developmental rates obtained with ICSI have been low, probably due to inappropriate oocyte activation or sperm capacitation that results in nonpronuclei formation. Many studies have been done on these subjects: in mice [3], rabbits [10], sheep [11] and horses [12]; ICSI by itself are sufficient for oocyte activation, sperm head decondensation and embryo development. In contrast, in cattle and pigs, ICSI was combined with chemical activation (ethanol [13]; Caionophore [7,14]; ionomycin alone $[15,16]$; or combined with 6-dimethilaminopurine (6-DMAP [15-17]) or electrical activation $[14,18,19]$ in order to improve activation of oocytes. Piezo-drill ICSI was reported to increase both activation and cleavage rates in horses [12,20], goats [9] and cows [21-23].

It is known that a permeabilisation treatment of the sperm membrane prior to ICSI helps the decondensation of head sperm. Equine [24] and cattle [25] have very stable sperm membranes that require cryopreservation or a strong promoter of spermatozoa capacitation such as ionomycin, which destabilizes plasma membranes thus increasing fertilisation rates. In goats, a stronger sperm treatment using heparin plus ionomycin improved in vitro fertilisation and embryo development results, both in adult [26] and prepubertal goats [27]. In our previous study, using fresh semen and manual needle injection ICSI, prepubertal goat oocytes needed chemical activation (ionomycin plus 6-DMAP) to be fertilised. However, chemical treatment also increased parthenogenetic embryos [28]. In order to avoid oocyte chemical activation, in the present study we will use a sperm pretreatment using heparin plus ionomycin before ICSI to destabilise the membrane so as to help sperm head decondensation.

The ICSI technique improved embryo development of prepubertal goat oocytes compared to the IVF protocol [28]. However, embryo development was low in both cases. Several studies have shown reduced embryo development of oocytes from prepubertal females (reviewed by [29]). In adult females, a positive relationship has been found between follicle diameter, oocyte diameter and the developmental competence of oocytes (reviewed by [30]). In cattle, follicles larger than $6 \mathrm{~mm}$ [31] provided the most competent oocytes. Moreover, other studies obtained the most competent oocytes when their diameter was $135 \mu \mathrm{m}[32,33]$.
Cattle oocyte diameter seems to be smaller than that of goat oocytes. Thus, bovine full meiotic competence is achieved with a follicle size of about $3 \mathrm{~mm}$, which corresponds to an oocyte diameter of about $110 \mu \mathrm{m}$ [32]. In cattle, the relationship between cleavage rate and oocyte diameter has been evaluated [34]: cleavage rates of 7, 41 and $55 \%$ were obtained for bovine oocytes smaller than 100, 100-109 and 100-119 $\mu \mathrm{m}$, respectively, and this percentage increased to $71 \%$ when oocytes were bigger than $120 \mu \mathrm{m}$. When embryo development was studied, oocytes smaller than $100 \mu \mathrm{m}$ and from 100 to $109 \mu \mathrm{m}$ triggered the lowest blastocyst rates (20 and 30\%, respectively) while oocytes from 100 to $129 \mu \mathrm{m}$ triggered the highest percentage $(60 \%)$. There was a small decrease in blastocyst percentages when oocytes measured more than $120 \mu \mathrm{m}$ (49\%).

In cattle [35] and sheep [36], oocytes from prepubertal females were found to be smaller than oocytes from adult females. In goats, de Smedt et al. [37] showed that adult goat oocytes sequentially acquired meiotic competence in follicles ranging from 0.5 to $2-3 \mathrm{~mm}$ in diameter, and Crozet et al. [38] observed that the mean oocyte diameter increased from $96 \pm 0.3$ to $136 \pm 0.6 \mu \mathrm{m}$ as follicle size increased from 0.5 to $2-3 \mathrm{~mm}$. In prepubertal goat oocytes, Martino et al. [39] also observed that meiotic competence acquisition was achieved with a follicle diameter of 2-3 mm with an oocyte diameter of $134 \pm 5.37 \mu \mathrm{m}$. In both, adult [37] and prepubertal goat oocytes [39], these authors observed that oocytes smaller than $110 \mu \mathrm{m}$ corresponded to incompetent meiotic oocytes, from 110 to $125 \mu \mathrm{m}$ they corresponded to partially competent oocytes and oocytes larger than $125 \mathrm{~mm}$ had full meiotic competence. No studies about the relationship between prepubertal goat oocyte diameter and embryo development have been carried out.

Thus, the aim of the present study was to determine embryo development competence of prepubertal goat oocytes according to their diameter and fertilisation by ICSI after a spermatozoa treatment with ionomycin and heparin.

\section{Materials and methods}

\subsection{Recovery and in vitro maturation of oocytes}

Ovaries from prepubertal goats (1-2 months old) were obtained from a local abattoir and transported to the laboratory in PBS solution Dulbecco's phosphatebuffered saline (PBS, P-4417, Sigma Chemical Co., St. Louis, MO, USA) with $50(\mathrm{~g} / \mathrm{ml}$ of gentamycin sulphate at $38.5^{\circ} \mathrm{C}$. The ovaries were rinsed with the same solution. The cumulus-oocyte complexes (COCs) were 
recovered after slicing the ovaries submerged in slicing medium: TCM199 (Sigma, M-2520), supplemented with $2.2 \mathrm{mg} / \mathrm{ml} \mathrm{NaHCO} 3,2 \%$ (v/v) steer serum (Donor Bovine Serum, CanSera, Ontario, Canada) and $50(\mathrm{~g} / \mathrm{ml}$ gentamycin at $38{ }^{\circ} \mathrm{C}$. Only $\mathrm{COCs}$ with at least four intact layers of compact cumulus cells and homogeneous cytoplasm were selected.

Selected COCs were washed in IVM medium. Groups of 20-25 COCs were matured in $100 \mu 1$ drops of IVM medium: TCM199 (Sigma, M-7528) supplemented with $275 \mu \mathrm{g} / \mathrm{ml}$ sodium pyruvate (Sigma, P-3662), $146 \mu \mathrm{g} / \mathrm{ml}$ L-glutamine (Sigma, G-5763), 10\% (v/v) steer serum, $10 \mu \mathrm{g} / \mathrm{ml} \quad o$-LH (Sigma, L-5269), $10 \mu \mathrm{g} / \mathrm{ml} \quad o$-FSH (Ovagen, Immuno Chemicals Products Ltd., Auckland, New Zealand), $1 \mu \mathrm{g} / \mathrm{ml} 17 \beta$ estradiol (Sigma, E-2257), $100 \mu \mathrm{M}$ cysteamine (Sigma, M-9768) and $50 \mu \mathrm{g} / \mathrm{ml}$ gentamycin. Oocytes were incubated for $27 \mathrm{~h}$ at $38.5^{\circ} \mathrm{C}$ in a humidified atmosphere of $5 \% \mathrm{CO}_{2}$ in air under mineral oil (Sigma, M-3516).

\subsection{In vitro fertilisation}

Fresh semen was collected by artificial vagina from 2 Murciano-Granadino bucks of proven fertility. The sperm motility was evaluated under a phase contrast microscope. The motile sperm fraction was selected by swim-up: $70 \mu \mathrm{l}$ of semen were placed in conical tubes under $2 \mathrm{ml}$ defined medium [40] modified by Younis et al. [41] referred here as $\mathrm{mDM}$, and incubated for $1 \mathrm{~h}$ in a humidified atmosphere of $5 \% \mathrm{CO}_{2}$ in air at $38.5{ }^{\circ} \mathrm{C}$. After incubation, $600 \mu \mathrm{l}$ from the supernatant was removed and centrifuged at $200 \times g$ for $10 \mathrm{~min}$. The sperm pellet was resuspended 1:1 with mDM medium containing heparin and ionomycin (Sigma, I-0634) (final concentration $10 \mu \mathrm{M}$ and $200 \mathrm{nM}$, respectively) and incubated for $15 \mathrm{~min}$ in a humidified atmosphere of $5 \% \mathrm{CO}_{2}$ in air at $38.5^{\circ} \mathrm{C}$.

After maturation, groups of 20-25 oocytes (IVF group) were placed into $100 \mu$ l fertilisation microdrops of modified Tyrode's medium (TALP), as described by Parrish et al. [42] and supplemented with $1 \mu \mathrm{g} / \mathrm{ml}$ hypotaurine (Sigma, H-1384) under mineral oil. The treated spermatozoa were co-incubated with the COCs for $24 \mathrm{~h}$ with a final concentration of $4 \times 10^{6}$ spermaspermatozoa $/ \mathrm{ml}$ in a humidified atmosphere of $5 \% \mathrm{CO}_{2}$ in air at $38.5{ }^{\circ} \mathrm{C}$.

\subsection{Oocyte diameter selection}

Only oocytes for ICSI groups were selected by their cytoplasmic diameter. Before sperm injection, oocytes were denuded by pipetting and their diameter was measured using a micrometric ocular under an inverted microscope. Oocyte diameter was measured (excluding the zone pellucida) as the mean length of two perpendicular axes. Oocytes were divided in four groups depending on their diameter: oocytes smaller than $110 \mu \mathrm{m}$ (Group A), oocytes from 110 to $125 \mu \mathrm{m}$ (Group B), from 125 to $135 \mu \mathrm{m}$ (Group C) and bigger than $135 \mu \mathrm{m}$ (Group D).

\subsection{Injection techniques}

After IVM, one oocyte (with the first polar body visible) per drop was placed into a microdrop of $5 \mu \mathrm{l}$ of injection TALP medium under mineral oil. The ICSI and Sham procedures were performed as described by Jimenez-Macedo et al. [28]. Briefly, ICSI oocytes were injected with one spermatozoon into the ooplasm with a minimum volume of medium $(<5 \mathrm{pl})$. Sham injections were performed in a similar manner without sperm cell but expelling a similar volume of PVP as in ICSI. The oolema was ruptured and the ooplasm was aspirated into the injection pipette and re-injected into the oocyte with a minimum volume of medium.

\subsection{In vitro embryo culture}

At $24 \mathrm{~h}$ post-insemination (hpi), in vitro fertilised oocytes were denuded. Groups of 16 presumptive zygotes were washed twice and placed into $20 \mu \mathrm{l}$ drops of SOF medium ([43] modified by [44]) for $192 \mathrm{~h}$. At 48 hpi, $0.1 \mu$ l of FBS (Sigma, F-7524) was added for each embryo. Embryos were cultured at $38.5^{\circ} \mathrm{C}$ in a humidified atmosphere of $5 \% \mathrm{CO}_{2}, 5 \% \mathrm{O}_{2}$ and $90 \% \mathrm{~N}_{2}$. Cleavage rate was evaluated at $48 \mathrm{hpi}$ and embryos were fixed at 192 hpi to evaluate their different developmental stages.

\subsection{Evaluation of different developmental stages after IVM, IVF/ICSI and IVC}

Zygotes were stained at $17 \mathrm{hpi}$ with $1 \%$ lacmoid (Sigma, L-7512) to evaluate the nuclear stage. Zygotes were categorized as normally fertilised if one female and one male pronuclei (2 PN) were formed. The male pronucleus was detected when one sperm tail was close to the pronucleus. Zygotes with 3 PN were considered as polyspermics in IVF group and activated in ICSI group.

Zygotes with $1 \mathrm{PN}$, were classified in two groups: pronucleus with a sperm head and pronucleus plus a metaphase spindle. 
Injected sham oocytes were considered activated when one or more pronuclei was observed.

Embryos were assessed with fluorescent microscopy after Hoechst 33342 staining. The percentage of total embryos (number of embryos obtained after 8 days of culture/oocytes), morulae (embryos with 16 or more cells without blastocoele) and blastocysts (embryos with 60 or more cells with blastocoele formation) was evaluated.

\subsection{Experimental design}

\subsubsection{Experiment 1}

The aim of this study was to evaluate the ability of prepubertal goat oocytes to form zygotes after ICSI procedure with sperm treated with a combination of ionomycin and heparin. We included a Sham-injected oocyte group as control of mechanical activation and an IVF group as control of fertilisation. We studied the nuclear stage of oocytes after insemination/injection to validate the ICSI protocol in comparison to other studies in goats. The nuclear stage of zygotes was evaluated at $17 \mathrm{hpi}$.

\subsubsection{Experiment 2}

The objective of this experiment was to analyse in vitro development of embryos from prepubertal goats obtained from IVM-oocytes after IVF or ICSI. The embryo development was examined after $192 \mathrm{~h}$ of culture in SOF medium. Sham group was eliminated from this and the next experiment because of the low number of activation obtained.

\subsubsection{Experiment 3}

In this experiment, we divided oocytes in four groups depending on their diameter to evaluate the effect of oocyte diameter on its competence to develop up to blastocysts stage after ICSI procedure.

\subsection{Statistical analysis}

Differences in results were assessed using chi-square test $\left(\chi^{2}\right)$ or Fisher test (Graph-Pad software, San Diego, California, USA). Differences with a $P<0.05$ were considered statistically significant.

\section{Results}

\subsection{Experiment 1}

Table 1 shows the nuclear stage of oocytes at $17 \mathrm{~h}$ after IVF, ICSI and Sham injection.
Table 1

Nuclear stage of prepubertal goat oocytes at $17 \mathrm{~h}$ post-insemination after ICSI, IVF and Sham procedures (replicates, 6)

\begin{tabular}{llll}
\hline & ICSI & IVF & SHAM \\
\hline Total oocytes & 115 & 323 & 66 \\
Total oocytes & $58(50.4) \mathrm{a}$ & $104(32.2) \mathrm{b}$ & $4(6.0) \mathrm{c}$ \\
$\quad$ with one or & & & \\
more PN & & & \\
$2 \mathrm{PN}$ & $47(40.9) \mathrm{a}$ & $86(26.6) \mathrm{b}$ & $2(3.0) \mathrm{c}$ \\
$3 \mathrm{PN}$ & $3(2.6)$ & $17(5.3)$ & 0 \\
$1 \mathrm{PN}$ & $8(6.9)$ & $1(0.3)$ & $2(3.0)$ \\
$1 \mathrm{PN}+$ sperm head & 4 & 0 & - \\
$1 \mathrm{PN}+$ MII & 4 & 1 & - \\
\hline
\end{tabular}

The values with different letters $(a-c)$ within each row differ significantly $(P<0.05)$. PN, pronucleus; MII, metaphase II.

The ICSI group provided $40.9 \%$ of normal fertilised zygotes ( $2 \mathrm{PN})$, thus percentage decrease to $26.6 \%$ in IVF group $(P<0.05)$. Abnormalities in fertilisation were observed both in ICSI and IVF groups without statistically significant differences. The percentage of 3 PN was 2.6 and $5.3 \%$ for ICSI and IVF, respectively, and the percentage of $1 \mathrm{PN}$ was 6.9 and $0.3 \%$, respectively. When we evaluate the origin of the eight oocytes with $1 \mathrm{PN}$ formed in the ICSI group, we observed that four were female pronuclei and four were male pronuclei. In IVF group, it has observed only one 1 $\mathrm{PN}$ and was a male pronucleus. In the Sham group, of 66 injected oocytes, four were activated (two oocytes with $1 \mathrm{PN}$ and two with $2 \mathrm{PN}$ ).

\subsection{Experiment 2}

Results of embryo development after 7 days of culture are presented in Table 2.

In this experiment, the percentage of embryos obtained at $192 \mathrm{~h}$ after fertilisation was higher in the ICSI $(54.6 \%)$ than in the IVF $(27.3 \%)$ group. The highest percentage of $8-16$ cell embryos was found at ICSI group (17.5\%) in comparison to IVF group $(8.1 \%)$

Table 2

Embryo development after 8 days post-insemination of prepubertal goat oocytes after ICSI and IVF procedures (replicates, 7)

\begin{tabular}{lcc}
\hline & ICSI & IVF \\
\hline Total oocytes inseminated & 97 & 271 \\
2-7 cell stage embryos $(\%)$ & $23(23.7)$ & $38(14.0)$ \\
$8-16$ cell stage embryos $(\%)$ & $17(17.5)$ & $22(8.1)$ \\
Number of morulae $(\%)$ & $8(8.2)$ & $10(3.7)$ \\
Number of blastocysts $(\%)$ & $5(5.1)$ & $4(1.5)$ \\
Number of morulae + & $13(13.4)$ a & $14(5.1) \mathrm{b}$ \\
$\quad$ blastocysts $(\%)$ & & \\
\hline
\end{tabular}

The values with different letters (a and $b$ ) within each row differ significantly $(P<0.05)$. 
Table 3

Embryo development after 8 days post-injection of prepubertal goat oocytes classified according to oocyte diameter (replicates, 8)

\begin{tabular}{lccrrrrr}
\hline & $\begin{array}{l}\text { Total MII-oocytes } \\
\text { injected }\end{array}$ & $\begin{array}{l}\text { Cleavage } \\
\text { at } 48 \text { hpi }^{\mathrm{a}}\end{array}$ & $2-7$ cells $^{\mathrm{b}}$ & $8-16$ cells $^{\mathrm{b}}$ & Morulae $^{\mathrm{b}}$ & Blastocyst $^{\mathrm{b}}$ & $\mathrm{M}^{\mathrm{B}}+\mathrm{B}^{\mathrm{b}}$ \\
\hline Group A $(<110 \mu \mathrm{m})$ & 3 & 1 & 1 & - & - & - & \\
Group B $(110-125 \mu \mathrm{m})$ & 53 & $32(60.3)$ & $22(68.7) \mathrm{a}$ & $8(25.0)$ & $2(6.2) \mathrm{a}$ & $0 \mathrm{a}$ & $2(6.2) \mathrm{a}$ \\
Group C $(125-135 \mu \mathrm{m})$ & 103 & $69(66.9)$ & $16(23.2) \mathrm{b}$ & $21(30.4)$ & $21(30.4) \mathrm{b}$ & $11(15.9) \mathrm{b}$ & $32(46.4) \mathrm{b}$ \\
Group D $(>135 \mu \mathrm{m})$ & 24 & $18(75.0)$ & $7(38.9) \mathrm{b}$ & $5(27.8)$ & $4(22.2) \mathrm{b}$ & $2(11.1) \mathrm{b}$ & $6(33.3) \mathrm{b}$ \\
\hline
\end{tabular}

The values with different letters (a and $b)$ within each column differ significantly $(P<0.05)$. MII, metaphase II; hpi, hours post-injection.

${ }^{a}$ The percentages were calculated from total MII-oocytes.

b The percentages were calculated from total cleavage at 48 hpi.

$(P<0.05)$, while a 23.7 and $14.0 \%$ of ICSI and IVF oocytes, respectively, remained at the $2-7$ cell stage. We did not find significant differences between the experimental groups in the percentage of morulae nor blastocyst although there was a tendency to be higher in the ICSI group. Thus, the percentage of morula plus blastoocyst was significantly higher in ICSI than IVF group (13.4\% versus $5.1 \%$, respectively; $P>0.05$ ).

\subsection{Experiment 3}

In this experiment we evaluated embryo development of ICSI fertilised oocytes previously divided in four groups based on oocyte diameter (Table 3). In Group A, we obtained only three oocytes after IVM with a visible first polar body, and only one cleaved up to two cells after ICSI. Due to the low number of matured oocytes obtained, no statistical analysis has been done to this group.

After $48 \mathrm{~h}$ post-injection, no statistical differences were found among B-D groups.

In Group B we obtained a higher percentage of embryos arrested at 2-7 cell stage than Groups C and D (68.7\% versus $23.2 \%$ and $38.9 \%$, respectively); but no differences were found between groups in 8-16 cells stage (25.0, 30.4 and $27.8 \%$, respectively).

A low embryo development at Group B compared to Groups $\mathrm{C}$ and $\mathrm{D}$ was observed in percentage of morulae (6.2\% versus 30.4 and $22.2 \%$, respectively), percentage of blastocysts $(0 \%$ versus $15.9 \%$ and $11.1 \%$, respectively) and percentage of morula plus blastocysts (6.2\% versus $46.4 \%$ and $33.3 \%$, respectively).

\section{Discussion}

The present study shows that conventional ICSI with a previous treatment of sperm cells combining ionomycin and heparin as capacitators, increases embryo development and blastocyst rates in prepubertal goat oocytes compared to previous studies where spermatozoa were only capacitated with heparin [28]. In agreement with other studies in cattle $[16,23,45]$, pretreatment of sperm cells could be useful in the development of ICSI embryos. In the present study, we also show that the percentage of morulae plus blastocysts obtained from prepubertal goat oocytes was significantly higher in oocytes fertilised by ICSI than by IVF. In adult goat oocytes, blastocysts were obtained by ICSI using the Piezo Driven injection [9] or by conventional ICSI [46] with frozen-thawed sperm. Strong sperm capacitation is not necessary, possibly because freezing procedures or piezo electric pulses are enough to desestabilise the sperm membrane. In some species, such as the rabbit [10], mouse [3] or sheep [11], conventional ICSI was sufficient to activate oocytes and to start embryo development. In other species, there is not a consensus on the need for activation to increase embryo development because the studies had conflicting conclusions. In some cases, it has been demonstrated that chemical or electrical activation is necessary to increase embryo development (cattle [47]; porcine [14,19]; caprine [28]) to obtain blastocysts. In others, Piezo Driven ICSI was employed to fertilise oocytes (cattle [21-23]; caprine [9]). Also, there are studies which showed that conventional ICSI was sufficient (caprine [46]; porcine [48]). Considering our results obtained in Experiment 1 with Sham-injected oocytes, we cannot consider that ICSI by itself is sufficient to activate oocytes parthenogenetically from prepubertal goats, as was observed in our previous study [28]. Suttner et al. [45] showed different results in embryo development depending on oocyte activation, sperm treatment and injection technique. Pretreatment of sperm cells with dithiothreitol (DTT) prior to ICSI has been demonstrated to increase embryo development in cattle $[23,45]$. Thus, results with ICSI not only depend on oocyte activation but also on correct sperm capacitation. The treatment of fresh spermatozoa with 
ionophore molecules in species with a very stable sperm membrane, like horses [24] and goats [27], was an efficient way to improve fertilisation results. As we observed in Experiment 2, embryo development was better, for both ICSI and IVF, when the spermatozoa were treated with heparin plus ionomycin, compared to treatment with only ionomycin as a capacitator: the technique used in our previous study [28].

The ICSI is a useful technique in the study of oocyte quality because it reduces the variation due to sperm penetration and it allows fertilisation of each one of the MII-oocytes. Oocytes recovered from prepubertal goat ovaries obtained at the slaughterhouse are very heterogeneous in growth and atresia. This heterogeneity could be the cause of large variability among experiments in in vitro embryo production. In goats, oocyte meiotic competence has been determined according to oocyte diameter in adult [37] and prepubertal females [39]. Following this classification, in Experiment 3, the percentage of blastocysts obtained from prepubertal goat oocytes bigger than $125 \mu \mathrm{m}$ (Groups C and D) was significantly higher than 110 $125 \mu \mathrm{m}$ (Group B) oocytes. We found no differences between oocytes from Groups C (15.9\%) and D $(11.1 \%)$. In our laboratory, Anguita et al. [49] obtained a higher blastocyst rate per cleaved oocyte in oocytes larger than $135 \mu \mathrm{m}$ (Group D, 20.4\%) compared to oocytes of 125-135 $\mu \mathrm{m}$ (Group C, 5\%) in oocytes fertilised by IVF. The difference between Groups $\mathrm{C}$ and D after IVF (5 and 20.4\%, respectively) and ICSI (15.9 and $11.1 \%$, respectively) may be due to the inability of Group C oocytes to be fertilised by IVF, although they are capable of development after a sperm injection. A low percentage of oocytes of $110-125 \mu \mathrm{m}$ diameter (Group B) were able to develop up to morulae after ICSI fertilisation, but they were unable to develop beyond the 8 -cell stage after IVF. The low number of injected oocytes smaller than $100 \mu \mathrm{m}$ (Group A) was due to the extremely low percentage of them arriving at metaphase II stage after in vitro maturation.

In adult goats, Crozet et al. [50] found a direct positive relationship between follicular diameter and embryo development, showing that blastocyst production was $6 \%$ with oocytes from follicles of 2 to $3 \mathrm{~mm}$, $12 \%$ from follicles ranging from 3.1 to $5 \mathrm{~mm}, 26 \%$ from follicles larger than $5 \mathrm{~mm}$ and $41 \%$ with ovulated oocytes. In prepubertal goats, the number of follicles per ovary larger than $3 \mathrm{~mm}$ was 1.1 and that larger $5 \mathrm{~mm}$ was practically inexistent [39], so the mean follicle size that we used in this study was smaller than $3 \mathrm{~mm}$. Despite this, the highest percentage of blastocysts obtained in the present study was $15.9 \%$, higher than those usually obtained in prepubertal goat oocytes. In a second study, Crozet et al. [38] described the relationship between follicle size and oocyte diameter and observed that the mean oocyte size was $96 \mu \mathrm{m}$ in follicles smaller than $0.5 \mathrm{~mm} ; 120 \mu \mathrm{m}$ for follicles of $0.5-0.8 \mathrm{~mm} ; 125 \mu \mathrm{m}$ for follicles of $1-1.8 \mathrm{~mm}$; $136 \mu \mathrm{m}$ for follicles of $2-3 \mathrm{~mm}$ and they maintained a constant size of $130-146 \mu \mathrm{m}$ in follicles larger than $3 \mathrm{~mm}$. In conclusion, it seems that meiotic oocyte competence is closely related to oocyte diameter, but embryo developmental competence would be more closely related to follicle diameter than to oocyte diameter.

Most studies have been made to determine the relationship between follicle diameter and the competence of the oocyte to develop up to the blastocyst stage, because oocytes are usually released by follicular puncture. In our study, in prepubertal goats, the size of ovaries and follicles means that ovaries can be released by slicing. In cattle, several groups reported that oocytes derived from follicles larger than $4 \mathrm{~mm}$ resulted in a higher percentage of blastocysts than those from smaller follicles, concluding that the follicle size at which developmental embryo competence is achieved coincides with the ability of the follicle in vivo to respond to FSH stimulation with rapid growth $\mathrm{t}$ (reviewed by [51]). Lonergan et al. [31] obtained $60 \%$ of blastocysts from oocytes recovered from follicles larger than $6 \mathrm{~mm}$. Comparing embryo development, Kauffold et al. [52] concluded that blastocyst yield was similar between calf and cows oocytes when the oocytes were recovered from follicles larger than $8 \mathrm{~mm}$ whereas the proportion of blastocysts was lower in calf than in cows when oocytes were recovered from 4 to 8 and from 2 to $3 \mathrm{~mm}$ follicles. However, these authors did not analyse the size of oocytes recovered from follicles of different diameters and female ages. Hyttel et al. [34] reported in cattle that oocytes of $100 \mu \mathrm{m}$ had full competence for the resumption of meiosis and oocytes of $110 \mu \mathrm{m}$ had full competence to complete maturation and to sustain embryo development, but lower numbers of blastocysts were obtained from oocytes of $110 \mu \mathrm{m}(30 \%)$ than from oocytes larger than $110 \mu \mathrm{m}(60 \%)$. Otoi et al. [53], classifying oocytes in six categories according to oocyte diameter, concluded that bovine oocytes larger than $115 \mathrm{~mm}$ had reached meiotic competence, but they should have a diameter larger than $120 \mathrm{~mm}$ to acquire embryo development competence. In prepubertal goats, Rodriguez et al. [54] observed that the oocyte size average was $136 \mu \mathrm{m}$ when oocytes were selected positively by Brilliant Cresyl Blue (BCB) test and they obtained 4\% 
of blastocysts. As can be observed by these studies, there is a difference in the oocyte size required to maintain embryo development between cattle and goats. These differences could be explained by the different sizes of oocytes between species.

Based on our results, we can conclude that conventional ICSI with sperm treated with heparin plus ionomycin improved fertilisation rates and embryo development, and that oocytes larger than $125 \mu \mathrm{m}$ are competent to develop to the blastocyst stage. However, the percentage of embryo development of these prepubertal goat oocytes was lower than for oocytes from adult females and this could be related to the follicle size.

\section{Acknowledgment}

Grant sponsor MEC; Grant number: AGL200404737-CO3-01-GAN.

\section{References}

[1] Hiramoto Y. Microinjection of the live spermatozoa into sea urchin eggs. Exp Cell Res 1962;27:416-26.

[2] Uehara T, Yanagimachi R. Behavior of nuclei of testicular, caput and cauda epididymal spermatozoa injected into hamster eggs. Biol Reprod 1977;16:315-21.

[3] Kimura Y, Yanagimachi R. Intracytoplasmic sperm injection in the mouse. Biol Reprod 1995;52:709-20.

[4] Catt SL, Catt JW, Gomez MC, Maxwell WM, Evans G. Birth of a male lamb derived from an in vitro matured oocyte fertilised by intracytoplasmic injection of a single presumptive male sperm. Vet Rec 1996;139:494-5.

[5] Cochran R, Meintjies M, Reggio B, Hylan D, Carter J, Pinto C, et al. Live foals produced from sperm-injected oocytes derived from pregnant mares. J Equine Vet Sci 1998;18:736-40.

[6] Martin MJ. Development of in vivo-matured porcine oocytes following intracytoplasmic sperm injection. Biol Reprod 2000;63:109-12.

[7] Goto K, Kinoshita A, Takuma Y, Ogawa K. Fertilization of bovine oocytes by the injection of immobilized, killed spermatozoa. Vet Res 1990;139:494-5.

[8] Karaki RZ, Samarraie SS, Younis NA, Lahloub TM, Ibrahim MH. Blastocyst culture and transfer: a step toward improved in vitro fertilization outcome. Fertil Steril 2002;77:114-8.

[9] Wang B, Baldassarre H, Pierson J, Cote F, Rao KM, Karatzas $\mathrm{CN}$. The in vitro and in vivo development of goat embryos produced by intracytoplasmic sperm injection using tail-cut spermatozoa. Zygote 2003;11:219-27.

[10] Keefer CL. Fertilization by sperm injection in the rabbit. Gamete Res 1989;22:59-69.

[11] Gomez MC, Catt JW, Evans G, Maxwell WM. Cleavage, development and competence of sheep embryos fertilized by intracytoplasmic sperm injection and in vitro fertilization. Theriogenology 1998;49:1143-54.

[12] Galli C, Croti C, Turini P, Duchi R, Mari G, Zavaglia G, et al. Frozen-thawed embryos produced by ovum pick up of immature oocytes and ICSI and capable to establish pregnancies in the horse. Theriogenology 2002;58:713-5.

[13] Hamano K, Li X, Qian XQ, Funauchi K, Furudate M, Minato Y. Gender preselection in cattle with intracytoplasmically injected, flow cytometrically sorted sperm heads. Biol Reprod 1999;60:1194-7.

[14] Probst S, Rath D. Production of piglets using intracytoplasmic sperm injection (ICSI) with flowcytometrically sorted boar semen and artificially activated oocytes. Theriogenology 2003;59:961-73.

[15] Chung JT, Keefer CL, Downey BR. Activation of bovine oocytes following intracytoplasmic sperm injection (ICSI). Theriogenology 2000;53:1273-84.

[16] Rho GJ, Kawarsky S, Johnson WH, Kochhar K, Betteridge KJ. Sperm and oocyte treatments to improve the formation of male and female pronuclei and subsequent development following intracytoplasmic sperm injection into bovine oocytes. Biol Reprod 1998;59:918-24.

[17] Fulka Jr J, Leibfried-Rutledge ML, First NL. Effect of 6dimethylaminopurine on germinal vesicle breakdown of bovine oocytes. Mol Reprod Dev 1991;29:379-84.

[18] Prochazka R, Durnford R, Fiser P, Marcus G. Pathenogenetic development of activated in vitro matured bovine oocytes. Theriogenology 1993;39:1025-32.

[19] Lee JW, Tian XC, Yang X. Failure of male pronucleus formation is the major cause of lack of fertilization and embryo development in pig oocytes subjected to intracytoplasmic sperm injection. Biol Reprod 2003;68:1341-7.

[20] Choi YH, Landim-Alvarenga FC, Seidel Jr GE, Squires EL. Effect of capacitation of stallion sperm with polyvinylalcohol or bovine serum albumin on penetration of bovine zona-free or partially zona-removed equine oocytes. J Anim Sci 2003;81: 2080-7.

[21] Katayose H, Yanagida K, Shinoki T, Kawahara T, Horiuchi T, Sato A. Efficient injection of bull spermatozoa into oocytes using a Piezo-driven pipette. Theriogenology 1999;52:1215-24.

[22] Wei H, Fukui Y. Births of calves derived from embryos produced by intracytoplasmic sperm injection without exogenous oocyte activation. Zygote 2002;10:149-53.

[23] Galli C, Vassiliev I, Lagutina I, Galli A, Lazzari G. Bovine embryo development following ICSI: effect of activation, sperm capacitation and pre-treatment with dithiothreitol. Theriogenology 2003;60:1467-80.

[24] Alm H, Torner H, Blottner S, Nurnberg G, Kanitz W. Effect of sperm cryopreservation and treatment with calcium ionophore or heparin on in vitro fertilization of horse oocytes. Theriogenology 2001;56:817-29.

[25] Perreault SD, Barbee RR, Elstein KH, Zucker RM, Keefer CL. Interspecies differences in the stability of mammalian sperm nuclei assessed in vivo by sperm microinjection and in vitro by flow cytometry. Biol Reprod 1988;39:157-67.

[26] Wang B, Baldassarre H, Tao T, Gauthier M, Neveu N, Zhou JF, et al. Transgenic goats produced by DNA pronuclear microinjection of in vitro derived zygotes. Mol Reprod Dev 2002;63: 437-43.

[27] Urdaneta A, Jimenez AR, Paramio MT, Izquierdo D. Cysteamine, glutathione and ionomycin treatments improve in vitro fertilization of prepubertal goat oocytes. Zygote 2004;12:277-84.

[28] Jimenez-Macedo AR, Izquierdo D, Anguita B, Paramio MT. Comparison between intracytoplasmic sperm injection and in vitro fertilisation employing oocytes derived from prepubertal goats. Theriogenology 2005;64:1249-62. 
[29] Armstrong DT. Effects of maternal age on oocyte developmental competence. Theriogenology 2001;55:1303-22.

[30] Gandolfi F, Brevini TA, Cillo F, Antonini S. Cellular and molecular mechanisms regulating oocyte quality and the relevance for farm animal reproductive efficiency. Rev Sci Technol 2005;24:413-23.

[31] Lonergan P, Monaghan P, Rizos D, Boland MP, Gordon I. Effect of follicle size on bovine oocyte quality and developmental competence following maturation, fertilization, and culture in vitro. Mol Reprod Dev 1994;37:48-53.

[32] Fair T, Hyttel P, Greve T. Bovine oocyte diameter in relation to maturational competence and transcriptional activity. Mol Reprod Dev 1995;42:437-42.

[33] Harada M, Miyano T, Matsumura K, Osaka S, Miyake M, Kato S. Bovine oocytes from early antral follicles grow to meiotic competence in vitro: effect of FSH and hypoxanthine. Theriogenology 1997;48:743-55.

[34] Hyttel P, Fair T, Callensen H, Greve T. Oocyte growth, capacitation and final maturation in cattle. Theriogenology 1997;47:23-32.

[35] Gandolfi F, Milanesi E, Pocar P, Luciano AM, Brevini TA, Acocella F, et al. Comparative analysis of calf and cow oocytes during in vitro maturation. Mol Reprod Dev 1998;49:168-75.

[36] Ledda S, Bogliolo L, Leoni G, Naitana S. Follicular size affects the meiotic competence of in vitro matured prepubertal and adult oocytes in sheep. Reprod Nutr Dev 1999;39:503-8.

[37] de Smedt V, Crozet N, Gall L. Morphological and functional changes accompanying the acquisition of meiotic competence in ovarian goat oocyte. J Exp Zool 1994;269:128-39.

[38] Crozet N, Dahirel M, Gall L. Meiotic competence of in vitro grown goat oocytes. J Reprod Fertil 2000;118:367-73.

[39] Martino A, Mogas T, Palomo M, Paramio M. Meiotic competence of prepubertal goats. Theriogenology 1994;41:969-80.

[40] Brackett BG, Oliphant G. Capacitation of rabbit spermatozoa in vitro. Biol Reprod 1975;12:260-74.

[41] Younis AI, Zuelke KA, Harper KM, Oliveira MA, Brackett BG In vitro fertilization of goat oocytes. Biol Reprod 1991;44:117782.

[42] Parrish J, Susko-Parrish J, Leibfried-Rutledge M, Crister E, Eyeston W, First N. Bovine in vitro fertilization with frozen thawed semen. Theriogenology 1986;25:591-600.
[43] Tervit HR, Whittingham DG, Rowson LEA. Successful culture of in vitro sheep and cattle ova. J Reprod Fertil 1972;30:493-7.

[44] Takahashi Y, First NL. In vitro development of bovine one-cell embryos: influence of glucose, lactate, pyruvate, amino acids and vitamins. Theriogenology 1992;37:963-78.

[45] Suttner R, Zakhartchenko V, Stojkovic P, Muller S, Alberio R, Medjugorac I, et al. Intracytoplasmic sperm injection in bovine: effects of oocyte activation, sperm pretreatment and injection technique. Theriogenology 2000;54:935-48.

[46] Keskintepe L, Morton PC, Smith SE, Tucker MJ, Simplicio AA, Brackett BG. Caprine blastocyst formation following intracytoplasmic sperm injection and defined culture. Zygote 1997;5:261-5.

[47] Keefer CL, Younis AI, Brackett BG. Cleavage development of bovine oocytes fertilized by sperm injection. Mol Reprod Dev 1990;25:281-5.

[48] Kim NH, Lee JW, Jun SH, Lee HT, Chung KS. Fertilization of porcine oocytes following intracytoplasmic spermatozoon or isolated sperm head injection. Mol Reprod Dev 1998;51:436-44.

[49] Anguita B, Jimenez-Macedo AR, Izquierdo D, Paramio MT. MPF activity and developmental competence in different sizes of prepubertal goat oocytes. Reprod Fertil Dev 2006;18(2):267-8. abst..

[50] Crozet N, Ahmed-Ali M, Dubos MP. Developmental competence of goat oocytes from follicles of different size categories following maturation, fertilization and culture in vitro. J Reprod Fertil 1995;103:293-8.

[51] Hendriksen PJ, Vos PL, Steenweg WN, Bevers MM, Dieleman SJ. Bovine follicular development and its effect on the in vitro competence of oocytes. Theriogenology 2000;53:11-20.

[52] Kauffold J, Amer HA, Bergfeld U, Weber W, Sobiraj A. The in vitro developmental competence of oocytes from juvenile calves is related to follicular diameter. J Reprod Dev 2005;51:325-32.

[53] Otoi T, Yamamoto K, Koyama N, Tachikawa S, Suzuki T. Bovine oocyte diameter in relation to developmental competence. Theriogenology 1997;48:769-74.

[54] Rodriguez-Gonzalez E, Lopez-Bejar M, Izquierdo D, Paramio MT. Developmental competence of prepubertal goat oocytes selected with brilliant cresyl blue and matured with cysteamine supplementation. Reprod Nutr Dev 2003;43:179-87. 